\title{
COMMON BACTERIAL ISOLATES FROM INFECTED EYES
}

\author{
BY \\ UBANI, UDO AHANNA \\ DEPARTMENT OF OPTOMETRY, FACULTY OF HEALTH SCIENCES, \\ ABIA STATE UNIVERSITY, UTURU, \\ ABIA STATE, NIGERIA.
}

\section{$T$}

ABSTRACT The common bacterial isolates and their antibiotics susceptibility were studied in 298 bacterial eye infected cases, consisting of 35 blepharitis, 208 conjunctivitis and 55 keratitis. The results yielded 333 bacterial isolates with the implicated bacteria in decreasing order of frequency as Staphylococcus aureus 80(23.70\%), Staphylococcus albus 65(19.20\%), Pseudomonas aeruginosa 34(10.10\%), Streptococcus pneumoniae 29(8.60\%), Haemophilus influenzae 26(7.70\%), Streptococcus pyogene 20(6.20\%), Klebsiella pneumoniae 18(6.20\%), Escherichia coli 15(4.40\%), Neisseria gonorrhoeae 13(3.90\%), Streptococcus viridans11(3.50\%), Moraxella catarrhalis 10(3.0\%), Streptococcus faecalis 5(1.50\%), Proteus mirabilis 5(1.50\%) and Neisseria meningitides 1(0.30\%). Bacteria were isolated most on the eye infections of the conjunctiva 222(66.70\%), then the cornea $65(20.10 \%)$, and least on the eyelids 44(13.20\%). Bacterial isolates varied in the clinical features; $p<0.01$. The age distribution showed an isolation of 77(23.20\%) and 79(23.70\%) in the age groups of $0-2+$ and 3-11+ respectively, which was comparable to 66(19.80\%) for the 12-17+; 18-39+ age groups $61(18.30 \%)$ and $50(15.0 \%)$ for the 40 s and above. Bacterial isolates had no predilection for age of patients ( $p<0.95)$. Klebsiella pneumoniae was the most resistant to all the anti bacterial preparations. The bacterial isolates were more susceptible to the $2^{\text {nd }}$ generation quinolones than the $1^{\text {st }}$ generations. The study recommends them to be available as ophthalmic preparations, to be dispensed by qualified practitioners to avoid development of resistance from indiscriminate use.

KEYWORDS: Blepharitis, conjunctivitis, keratitis, bacterial isolates and antibiotics susceptibility.

\section{INTRODUCTION}

Pathogenic microorganisms cause diseases to the eyes due to their virulence and host's reduced resistance from many factors such as personal hygiene, living conditions, socio-economic status, nutrition, genetics, physiology, fever and age ${ }^{1}$. The areas in the eye that are frequently infected are the conjunctiva, lid and cornea ${ }^{2}$.

In infections of the lids, the anterior lid margins show hyperamia, telangiectasis, and scaling. The scales are hard and brittle and tend to be centered on the bases of the lashes. When removed they may leave behind a tiny bleeding ulcer. In severe cases the lashes may become matted down by yellow crust. Spread of the infection to the glands of Zeis and Moll may give rise to an acute external hordeolum (stye) and spread to the meibomian glands may give rise to an internal hordeolum.

Conjunctivitis presents with an acute onset of redness, grittiness, burning and discharge. Photophobia may be present if there is associated severe punctate epitheliopathy or peripheral corneal infiltrates. On waking in the morning, the eyelids are frequently stuck together and difficult to open as a result of the accumulation of exudates during the night. Both eyes are usually involved; although one may become affected before the other. $^{3}$. Visual acuity is usually normal in the absence of severe punctuate epitheliopathy.

In keratitis, certain bacteria produce characteristic corneal responses. Staphylococcus aureus (S.aureus) and Streptococcus pneumoniae (S.pneumoniae) tend to produce oval, yellowwhite, densely opaque stromal suppuration surrounded by relatively clear cornea. Pseudomonas spp. typically cause irregularly shaped ulceration, thick mucopurulent exudates, diffuse liquifactive necrosis and semi-opaque "ground-glass" appearance of adjacent stroma. The infection may progress rapidly and result in corneal perforation within 48 hours. Enterobacteriaceae usually cause a shallow ulceration, grey-white pleomorphic suppuration and diffuse stromal opalescence. The endotoxins present in gram-negative bacteria may induce ringshaped corneal infiltrates.

Infection of the eye is a problem, for a loss or impairment of visual function is a major disability, the structures of the eye are particularly delicate and degree of scarring or inflammation which will 
be relatively minor in other parts of the body, may have quite a serious consequence in the eye. Hence bacterial eye infection is an ophthalmic emergency that needs immediate institution of treatment ${ }^{4}$. Medical management of bacterial eye infections may involve treatment with broad spectrum antibiotics. This is most at times before pathogen identification and antibiotic susceptibility tests are available. This together with indiscriminate use of antibiotics have led to the development of resistance to many commonly used anti microbial medications ${ }^{5,6,7}$.

This research, therefore, aims amongst others at evaluating the antibiotic sensitivity of the bacterial organisms isolated from the eye infections amongst people living in Aba, studying the distribution of the common bacterial isolates in the clinical features-conjunctivitis, blepharitis and keratitis, the distribution of these bacterial isolates amongst age groups and the distribution of these bacterial isolates between males and females.

\section{RESEARCH METHODOLOGY}

The research was a prospective, clinical laboratory study on bacterial isolation from infected eyes and their in vitro antibiotics susceptibility. These were studied on patients who visited the eye clinics in Abia State University Teaching Hospital and Niger Optical Service Company, all in Aba, South Eastern Nigeria in the period of January 2005 December 2006.

Material for culture was collected soon after the onset of infection (24 to 48hrs) and inoculated into the culture media- nutrient, blood and chocolate agars. This was before the instillation of antimicrobial or steroidal eye drops for treatment.

A total of 298 samples were collected from the actual sites of infections - 35 from the lid margin, 208 from the conjunctiva and 55 from the cornea.

The isolation of bacteria was done by incubating the agar plates at temperature of $37^{\circ} \mathrm{C}$. Aerobic atmospheric condition was maintained for the blood agar, while $10 \%$ carbon dioxide $\left(\mathrm{CO}_{2}\right)$ atmosphere was for the chocolate agar. Mixed colonies observed were purified by repeated subculturing on media originally used for their isolation. Pure culture from the continuous subculturing was stored in nutrient agar slants for further tests.

Gram's cell wall, capsule and spore staining tests, followed by tests demonstrating motility; the presence of the enzymes-Catalase, Coagulase, Oxidase and Amylase. Isolates sugar fermentation properties, that is, with or without the production of acid and gas. Methyl red and Voges Proskaeur tests to detect the production of sufficient acid during the fermentation of sugar; ability to decompose the amino acid Tryptophan to Indole; ability to utilize citrate as sole source of carbon and energy; and ability to utilize ammonium salt as the sole source of nitrogen. As well as the production of hydrogen sulphate from sulphur- containing amino acids were the biochemical tests performed. . $9,10,11,12^{\text {. }}$.

In the antibiotics susceptibility test (KirbyBauer Disk Diffusion Method), the uniformly inoculated agar plate containing the paper disks impregnated with fixed concentrations of the antibiotics was incubated soon after placing the paper disks, since the test is standardized under conditions where diffusion of the antibiotic and bacterial growth commences at approximately the same time. ${ }^{13}$ Following an overnight incubation, the diameter of the zone of growth inhibition around each disk was measured to the nearest whole millimeter. The strain's susceptibility to the antibiotics was determined using a standard table of antibiotic susceptibility. The susceptibility of bacterial agents to the antibiotics was presented in percentage.

In calculating the test statistics the mean of squares were determined using the computational formulae $^{14}$. The cumulative probabilities were found in the Fisher's $F$-distribution. The hypothesis that ocular clinical features have no predilection for sex was tested in the Student's $t$ values.

\section{RESULTS}

There were a total of 298 bacterial infections (of the lids, conjunctiva and cornea) from which swabs or scrapping as the case may be were collected and cultured. The result was an isolation of 333 bacteria comprising of the $S$. aureus, Staphylococcus albus (S. albus), Streptococcus pyogenes (S. pyogenes), $S$. pneumoniae, Streptococcus faecalis (S. faecalis), Streptococcus viridans (S. viridans), Neisseria meningitides ( $N$. meningitides), Neisseria gonorrhoeae ( $N$. gonorrheae), Moraxella catarrhalis (M.catarrhalis) and the Enteric bacteria Klebsiella pneumoniae (K.pneumoniae), Proteus mirabilis (P. mirabilis), Eshcerichia coli (E. coli), Pseudomonas aeruginosa ( $P$. aeruginosa) and Haemophilus influenzae (H.influenzae; Table 1).

The Staphylococcus (on the culture media) were round smooth, raised, glistering and produced 
pigments that varied from white to deep yellow. Microscopic examinations of smears show gram positive spherical cells arranged in grape-like irregular clusters. They were non-motile and did not form spores. They fermented carbohydrates producing lactic acid but not gas. Two species were identified; $S$. aureus were coagulase positive which differentiated it from $S$. albus. They were highly sensitive to chloramphenicol $(80 \%)$, cephalexin (80\%), and were not sensitive to penicillin.

The Staphylococci produced catalase, which differentiated them from the Streptococci which were also gram positive spherical bacteria that formed pairs of chains. Four species of Streptococci were identified- pyogenes, viridans, faecalis and pneumoniae. S. pyogenes were $\beta$ hemolytic highly sensitive to augumentin (90\%) and penicillin (90\%) and less (20\%) to ofloxacin.

The $S$. pneumoniae were $\alpha$-hemolytic and optochin sensitive. They fermented glucose with production of lactic acid. They were $90 \%$ sensitive to penicillin, chloramphenicol and augumentin. $S$. pneumoniae were resistant to nalidixic acid and gentamycin. The $S$. viridans were $\alpha$-hemolytic or non-hemolytic. They were not inhibited by optochin. They were $95 \%$ sensitive to chloramphenicol, $80 \%$ to penicillin, nalidixic, augumentin and cephalexin. They were just $20 \%$ sensitive to ofloxacin. $S$. faecalis were nonhemolytic and occasionally $\alpha$-hemolytic. They were only $20 \%$ sensitive to ofloxacin and cephalexin but highly sensitive to gentamycin and nalidixic acid.

The Neisseriaceae were M. catarrhalis and the Neisseria species of gonorrhoeae and meningitidis. They were non-motile gramnegative cocci that were kidney shaped occurring in pairs and with flat or concave sides adjacent. Gonococci and Meningiococci formed convex glistering elevated mucoid colonies about $1-5 \mathrm{~mm}$ in diameter. They were transparent or opaque, nonpigmented and non-hemolytic gram-negative cocci that were kidney shaped occurring in pairs and with flat or concave sides adjacent. $M$. catarrhalis were also non-pigmented with pinkishgray opaque colonies. They produced oxidase and fermented carbohydrate producing acid but not gas. Gonococci fermented only glucose. $M$. catarrhalis was differentiated by its lack of carbohydrate fermentation.

The enterobacteriaceae were characterized as gram-negative rods being either motile or nonmotile. They fermented rather than oxidize glucose with gas production. They were catalase positive and oxidase negative. Five bacteria genera were isolated in the study- $P$. aeruginosa, E. coli, $K$. pneumoniae, $P$. mirabilis and $H$. influenzae. The $P$. mirabilis deaminated phenylalanine and were motile. They fermented xylose but lactose very slowly or not at all. They were not sensitive to penicillin. $K$. pneumoniae were non-motile and had large, very mucoid colonies. The organisms were positive to Voges Prauskaeur and citrate. They were not sensitive to penicillin but moderately sensitive to cephalexin and nalidixic acid $(45 \%)$.

$P$. aeruginosa in culture media produced a sweet or grape-like odor. Some strains hemolyzed blood. They formed smooth round colonies, with fluorescent greenish colour and often a nonfluorescent bluish pigment, which diffused into the agar. They were oxidase positive and did not ferment carbohydrate, but oxidized glucose. They were not sensitive to penicillin. They were $10 \%$ sensitive to chloramphenicol; and highly sensitive to ciprofloxacin and gentamycin $(90 \%)$. The $H$. influenzae were coccoid bacilli occurring in pairs and short chains. They were differentiated by their requirement of $\mathrm{x}-\& \mathrm{v}$ - factor which is maintained in the chocolate agar. They were not hemolytic and fermented carbohydrates poorly. Many were susceptible to chloramphenicol and the second generation quinolones.

The result in Table 2 shows 77 bacterial isolates in the age group $0-2^{+}, 25(32.5 \%)$ of this were $S$. aureus and 23(29.9\%) were S. albus. $H$. influenzae were 6(7.8\%) isolations. S. pneumoniae and $S$. pyogenes were $4(5.2 \%)$ isolates each. $N$. gonorrhoeae and the enteric bacteria- $E$. coli, $K$. pneumoniae, and $P$. aeruginosa had 3(3.9\%) isolations each from this age group. $N$. meningitidis, $M$. catarrhalis and P. mirabilis were not isolated.

The age group $3-11^{+}$had 79 isolations and $S$. aureus and albus combined made 50\% (40 of the 79 ) of these bacterial isolations. The age group 12$17^{+}$did not record any isolation from $N$. meningitidis and $P$. mirabilis. The highest isolation was still from $S$. aureus $15(22.7 \%)$ of the $66, S$. albus was $10(15.2 \%)$. H. influenza and $P$. aeruginosa were $8(12.1 \%)$ each. The other enteric bacteria $K$. pneumoniae and E. coli were $5(7.6 \%)$ and $3(4.5 \%)$ respectively. $S$. aureus and $S$. pneumoniae each were $10(20 \%)$ of the 50 bacterial isolates of the $40 \mathrm{~s}$ and above. P. aeruginosa, $S$. pyogenes and S. albus were next 6(12\%), 6(12\%) and $5(10 \%)$ respectively. The Streptococci spp. of pyogenes, pneumoniae viridans and faecalis were $76(22.8 \%)$ of the 333 total bacterial isolates. 
Though more of these were from eye infections of the adults $15(19.7 \%)$ of the 76 in the $18-39^{+}$and $18(23.7 \%)$ in the $40 \mathrm{~s}$ and above. Infants $0-2^{+}$and the $3-11^{+}$each had eleven $(14.5 \%)$. While $N$. gonorrhoeae was isolated 3(23\%) each in the age groups $0-2^{+}, 12-17^{+}$and the $18-39^{+}$. Bacterial isolates did not vary with age of patients ( $p<0.95)$.

In Table 3, the age group $12-17^{+}$had the highest figure of blepharitis $15(42.80 \%)$ of 35 cases. Blepharitis was evenly diagnosed in the other age groups with a mean of $5(14.0 \%)$. The age groups 0 $2^{+}$and $3-11^{+}$recorded the highest cases of conjunctivitis $60(28.80 \%)$ and 53(25.50\%) of 208 respectively. Conjunctivitis was least $30(14.40 \%)$ each in the $18-39^{+}$and in the $40 \mathrm{~s}$ and above. In the $18-39^{+}$keratitis occurred highest $20(36.40 \%)$ of 55 , and $15(27.30 \%)$ in the 40 s and above. It was least in the $0-2^{+}$age group $4(7.20 \%)$ of 55 . There was a relationship between ocular clinical features and age of patient $(\mathrm{p}<0.99)$.

This study involved 139 males and 159 females. Conjunctivitis was 94(67.60\%) of 139 of the eye infections in males; and $114(71.70 \%)$ in females. Blepharitis cases was $15(10.80 \%)$ in males and 20(71.70\%) in females. Males recorded a higher case of keratitis 30(54.50\%) of 55 than females $25(45.5 \%)$. There was no relationship between sex and clinical features $(\mathrm{p}<0.75)$.

\section{DISCUSSION}

The study showed that bacteria cause the most ocular infections on the conjunctiva $222(66.70 \%)$ then on the cornea $67(20.10 \%)$ and least on the lids $44(13.20 \%)$. This agrees with Therese and Madhavan $^{15}$ as well as Levi ${ }^{16}$. Blepharitis occurred most in the $12-17^{+}$group $15(42.90 \%)$ of 35 . This may not be unrelated to the general changes on the skin of the face that go with puberty. Corneal infections occurred most in the $18-39^{+}$and the 40 s and above age groups (the working class). This may have come as occupational hazards in the abundant fabricating industries in the city of Aba. The age groups $0-2^{+}$had the highest number of bacterial ocular infections about $68(22.80 \%)$ of 298. These agree with the work of Madarres ${ }^{17}$. According to Prescott ${ }^{1}$, susceptibility to infection increases for babies because they are at a greater risk after their maternal immunity has disappeared and before their own immunity system had matured. Three $(23.0 \%)$ of $13 \mathrm{~N}$. gonorrhoeae isolation was recorded in the $0-3^{+}$and the $18-39^{+}$a sexually active age group. Gonococci eye infections in neonates are due to exposure of the babies to an infected birth canal.

The implicated bacteria in order of decreasing frequency were $S$. aureus $80(23.70 \%)$, S. albus $65(19.20 \%), \quad P$. aeruginosa $34(10.10 \%), \quad S$. pneumoniae $29(8.60 \%)$, H. influenzae $26(7.70 \%)$, $S$. pyogenes $20(6.20 \%), K$. pneumoniae $29(6.20 \%)$, E. coli $15(4.40 \%)$, N. gonorrhoeae 13(3.90\%), S. viridans 22(3.50\%), M. catarrhalis 10(3.0\%), S. faecalis 5(1.50\%), P. mirabilis $5(1.50 \%)$, and N. meningitidis $(0.30 \%)$.

There was no case of Diphtheriae, Pertusis and Tetanus bacterial ocular infection (in children). This may be highly attributed to the national immunization programmes currently initiated by the Federal Ministry of Health in Nigeria which has reduced the generally reported cases of these aetiologic agents. This study also showed lower isolations of the enteric bacteria when compared to earlier works ${ }^{17,18}$. This low enterobacteriaceae cases may be due to reduction in hand-faecal contamination of the eye due to availability of potable water sources in most house-holds and neighborhoods.

In Table $1, S$. aureus and coagulase negative albus were the most frequently isolated bacteria from infected eyelid margins, conjunctiva and cornea. These can be compared to Modarres et $\mathrm{al}^{17}$, where staphylococci were isolated $25.0 \%$ from blepharitis, $26.25 \%$ from conjunctivitis and $18.80 \%$ from Keratitis. S. aureus high pathogenicity is attributed to their being able to multiply and spread widely in tissues through their production of many extra cellular substances like coagulase which deposits Fibrin on the surface of the microorganism altering their ingestion by phagocytic cells; alpha toxin (hemolysin) which lyse erythrocyte and damage platelets ${ }^{1,9}$. The coagulase negative $S$. albus were next in frequency. Though they are normal flora of the eye $^{9}$, they caused infection in the immuno compromised patients; $10(15.40 \%)$ of 65 on the lids, $40(61.50 \%)$ on the conjunctiva and $15(23.0 \%)$ on the cornea. Of equal etiology in keratitis was $P$. aeruginosa. Also a normal flora of the cornea causes infection in mechanical trauma of the cornea when epithelium/stroma is disrupted by direct tissue damage. They produce exotoxin A which causes tissue necrosis-corneal ulcer'.

There was only a single case of $N$. meningitides in the study; on a 3year-old girl who traveled down from the northern part of the country during the month of February in the year of study (the northern part of the country is an arid region of Sub-Saharan Africa which is associated with 
outbreaks of $N$. meningitidis during the hot dry season of harmattan). This case was managed with a $3^{\text {rd }}$ generation cephalosporin. The Cephalosporins are B-lactam compounds with a nucleus of 7 amino cephalosporanic acid. Their antimicrobial action is through inhibition of cell wall. They attach to receptors inhibiting peptidoglycan synthesis. ${ }^{19}$ Resistance to them is determined by the organism production of betalactamases. Beta lactamases open the B-lactam ring and abolish their anti-microbial activity. Cephalexin a first generation cephalosporin used in the disk diffusion susceptibility test was very active against most gram positive cocci (between $70.0 \%$ and $80.0 \%$ susceptibility). It was moderately active against the gram negative rods$50.0 \%$ for $E$. coli, and $45.0 \%$ for $K$. pneumoniae and P. mirabilis.

Another B-lactam- penicillin (nucleus of 6aminopenicillanic acid) was most sensitive to Streptococci species and $N$. meningitidis. Amoxicillin which is a better absorbed penicillin given together with clavulanic acid was active against B-lactamase producing $H$. influenzae. Thus augumentin in this study showed a $100 \%$ sensitivity to $H$. Influenzae (Table 4). Clavulanic acid is a B-lactamase inhibitor that has a high affinity for and irreversibly binds some Blactomases. Clavulanic acid protects the simultaneously present hydrolysable penicillin (amoxicilin) from destruction.

As sensitivity to antibiotics is variable in bacterial isolates and recent studies have shown increasing resistance to most antibiotics ${ }^{20,21}$, with past literatures reporting indiscriminate use of antibiotics as the reason for drug resistance in microbial population ${ }^{20}$. In the study, chloramphenicol eye drop a potent broad spectrum antibiotics which is highly sensitive to the gram positive cocci and most gram negative bacilli should be protected from indiscriminate use and should not be acquired over-the-counter. It is widely prescribed for external ocular infections and dubiously as placebo by practitioners. The $2^{\text {nd }}$ generation quinolones (the fluorinated derivatives of ciprofloxacin and ofloxacin) were highly susceptible. They have a greater antibacterial activity and low toxicity ${ }^{9,22}$. Unfortunately ophthalmic preparations containing these antibiotics as active ingredients are not available in our local store for dispensing. This leaves a call to the pharmaceutical companies for better ophthalmic preparations with novel antibiotics.

\section{REF E R E N C E S}

1 Prescott, L. M., Harley, J. P. and Klein, D. A. (2002): Microbiology. $5^{\text {th }}$ Edn. McGrawHill Education Publisher, Madison, New York, pp 667-763.

2 Alfonso, E. and Miller, D. (1990): Detection of ocular infections: Clinical Application of the limulus Amoebocyte lysate Test. CRC Press, Boca Raton, Florida, 121pp.

3 Kanski, J. (1998): Disorders of the conjunctiva. Clinical Ophthalmology: A systematic approach. $3^{\text {rd }}$ Edn. ButterworthHeinemann, Jordan Hill, New York, pp71-95.

4 Smith, R. E. and Flowers, C. W. (1995): Chronic blepharitis. A Review. CLAO J, 21:2000-7.

5 Kunimoto, D. Y., Sharma, S., Garg, P. and Rao, G. N. (1999): In vitro susceptibility of bacterial keratitis pathogens to ciprofloxacin emerging resistance. Ophthalmol, 106: 80-5.

6 Goldstein, M. H., Kowalski, R. P. and Gordon, Y. L. (1999): Emerging fluroquinolones resistance in bacterial keratitis. Ophthalmol, 106: 1313-8.

7 Garg, P., Sharma, S. and Rao, G. N. (1999): Ciprofloxacin resistant pseudomones keratitis. Ophthalmol, 106: 1319-423.

8 Baker, F., Silverton, R. C. and Pallister, C. J. (2002): Introductory to Medical Laboratory Technology. 70 ${ }^{\text {th }}$ Edn. Bounty Press Ltd London, pp299-315.

9 Brooks, G. F., Butel, J. S. and Morse, S. A. (2002): Pseudomonas, Acinetobacters and uncommon Gram Negative Bacteria. In: Jawety, Melnick and Adelbegys Medical Microbiology. $22^{\text {nd }}$ Edn. McGraw-Hill, Madison, New York, pp229-34. 
10 Jones, D. B., Leisegang, T. J. and Robinson, N. M. (1981): Laboratory diagnoses of ocular infections. Am. Soc. Microbiol, 11:111-9.

11 MacFaddin, J. F. (2002): Biochemical tests for identification of medical bacteria $3^{\text {rd }}$ Edn. Lippincott William and Wilkins. Philadelphia, 650pp.

12 Forbes, B. A., Sahm, O. F. and Weissfeld, A. S. (2002): Diagnostic Microbiology In: Bailey and Scotts $11^{\text {th }}$ edn. The C. V. Mosby Company, pp229-50.

13 Agarwal, K. C. (1974): Antibiotics sensitivity test by disk diffusion method: standardization and interpretation. Ind J. Path Bact. 17:149-55.

14 Frank, H. and Althoen, S. (2002): Statistics:Concepts and application. Cambridge University Press, Cambridge, 853pp.

15 Therese, K. L. and Madhavan, H. N. (2004): Microbiological procedures for Diagnosis of ocular infections. Ind J Med. Microbiol, 41:834-53.

16 Levi, R. M. (1981): Etiology of conjunctivitis. J. Paediatr. 99(5):831-2.

17 Modarres, S. H., Lasheic, N. and Nassari, O. (1991): Bacterial etiologic agents of ocular infection in children in the Islamic Republic of Iran. Eastern Mediterranean Hlth.J,4(1):44-9.

18 Behraman, R. E. and Vaughan, V. C. (1989): Nelson Textbook of Pediatrics. Vol. 2, W. B. Sauders Company,.Philadelphia, 330pp.

19 Maellering, R. C. (2001): Anti infective therapy. In: Mandell, Douglas and Bennett's Principles and Practice of infectious Diseases, $5^{\text {th }}$ Edn. Churchill Livingstone, 690pp.

20 Tenover, F. C., Mohammed, M. J., Stelling, J., O'Brien, T., and Williams, R. (2001): Ability of laboratories to detect emerging antimicrobial resistance: proficiency testing and quality control results from the world health organizations external quality assurance system for antimicrobial susceptibility testing. J. Clin. Microbiol, pp241-50.

21 Smitha, S., Lalitha, P., Pnajna, V. and Srinivas, M. (2005): Susceptibility trends of pseudomonas species from corneal ulcer. Ind. J. Med. Microbiol, 23 (3):168-71.

22 Idu, F. K. and Odjimogbo, S. E. (2003): Susceptibility of conjunctival bacterial pathogens to fluroquinolones: a comparative study of ciprofloxacin Norfloxacin and Ofloxacin. Hlth. Allied Sci. 3 (2):11-7.

TABLE 1: DISTRIBUTION OF BACTERIAL ISOLATES IN CLINICAL FEATURES

\begin{tabular}{|l|l|l|l|}
\hline & Blepharitis & Conjunctivitis & Keratitis \\
\hline Organisms & $\mathbf{N}(\boldsymbol{\%})$ & $\mathbf{N}(\boldsymbol{\%})$ & $\mathbf{N}(\boldsymbol{\%})$ \\
S. aureus & $20(45.50)$ & $45(20.30)$ & $15(22.40)$ \\
S. albus & $10(22.70)$ & $40(18.0)$ & $15(22.40)$ \\
S. pyogenes & $6(13.60)$ & $13(5.86)$ & $1(1.50)$ \\
S. pneumoniae & $4(9.0)$ & $23(10.40)$ & $2(3.0)$ \\
S. viridans & $1(2.30)$ & $10(4.50)$ & $*$ \\
S. faecalis & $*$ & $5(2.25)$ & $*$ \\
N. meningitidis & $*$ & $1(0.45)$ & $*$ \\
N. gonorrhoeae & $*$ & $12(5.40)$ & $1(1.5)$ \\
M. cotarrhalis & $*$ & $10(4.50)$ & $*$ \\
E. coli & $*$ & $1(0.45)$ & $15(22.40)$ \\
K. pneumoniae & $3(6.80)$ & $15(6.75)$ & $*$ \\
P. mirabilis & $*$ & $5(2.25)$ & $*$ \\
H. influenzae & $*$ & $23(10.40)$ & $3(4.48)$ \\
P. aeruginosa & $*$ & $19(8.56)$ & $15(22.40)$ \\
\hline Total & $\mathbf{4 4 ( 1 0 0 )}$ & $\mathbf{2 2 2}(\mathbf{1 0 0})$ & $\mathbf{6 7}(\mathbf{1 0 0})$ \\
\hline
\end{tabular}

$\mathbf{N}=$ Number isolated

$*=$ Not isolated 
TABLE 2: FREQUENCY OF BACTERIAL ISOLATES IN RELATION TO AGE OF PATIENTS

\begin{tabular}{|c|c|c|c|c|c|}
\hline \multirow[b]{2}{*}{ Organisms } & \multicolumn{5}{|c|}{ Age } \\
\hline & $\begin{array}{l}\text { 0-2+ } \\
\mathbf{N}(\%)\end{array}$ & $\begin{array}{l}\text { 3-11+ } \\
\text { N }(\%)\end{array}$ & $\begin{array}{l}\text { 12-17+ } \\
\mathbf{N}(\%)\end{array}$ & $\begin{array}{l}\text { 18-39+ } \\
\text { N (\%) }\end{array}$ & $\begin{array}{l}\text { 40\& above } \\
\text { N }(\%)\end{array}$ \\
\hline S. aureus & $25(32.50)$ & $20(25.30)$ & $15(22.70)$ & $10(16.40)$ & $10(20.0)$ \\
\hline S. albus & $23(29.90)$ & $20(25.30)$ & $10(15.20)$ & $7(11.50)$ & $5(10.0)$ \\
\hline S. pyogenes & $4(5.20)$ & $3(3.80)$ & $3(4.50)$ & $5(8.20)$ & $6(10.0)$ \\
\hline S. pneumoniae & $4(5.20)$ & $5(6.30)$ & $4(6.10)$ & $6(9.80)$ & $10(20.0)$ \\
\hline S. viridans & $2(2.60)$ & $2(2.50)$ & $2(3.0)$ & $3(4.90)$ & $2(4.0)$ \\
\hline S. faecalis & $1(1.30)$ & $1(1.30)$ & $1(1.50)$ & $1(1.60)$ & $1(2.0)$ \\
\hline N. meningitidis & $\mathrm{x}$ & $1(1.30)$ & $\mathrm{x}$ & $\mathrm{X}$ & $\mathrm{X}$ \\
\hline N. gonorrhoeae & $3(3.90)$ & $2(2.50)$ & $3(4.50)$ & $3(4.90)$ & $2(4.0)$ \\
\hline M. catarrhali & $\mathrm{X}$ & $2(2.50)$ & $4(6.10)$ & $3(4.90)$ & $1(2.0)$ \\
\hline E. coli & $3(3.90)$ & $2(2.50)$ & $3(4.50)$ & $3(4.90)$ & $5(10.0)$ \\
\hline K. pneumoniae & $3(3.90)$ & $4(5.10)$ & $5(7.60)$ & $6(9.80)$ & $\mathrm{x}$ \\
\hline$P$ mirabilis & $\mathrm{X}$ & $1(1.30)$ & $\mathrm{X}$ & $2(3.30)$ & $2(4.0)$ \\
\hline H. influenzae & $6(7.80)$ & $6(7.60)$ & $8(12.0)$ & $3(4.90)$ & $3(6.0)$ \\
\hline P. aeruginosa & $3(3.90)$ & $8(10.10)$ & $8(12.0)$ & $9(14.40)$ & $6(12.0)$ \\
\hline Total & 77 & 79 & 66 & 61 & 50 \\
\hline
\end{tabular}

$\mathbf{N}=$ Number isolated

$*$ = Not isolated

TABLE 3: OCULAR CLINICAL FEATURES IN RELATION TO AGE AND SEX OF SAMPLED PATIENTS

\begin{tabular}{|c|c|c|c|c|c|c|c|}
\hline Clinical Features & \multicolumn{2}{|c|}{ Sex } & \multicolumn{5}{|c|}{ Age } \\
\hline & $\begin{array}{l}\text { Male } \\
\mathrm{N}(\%)\end{array}$ & $\begin{array}{l}\text { Female } \\
\mathrm{N}(\%)\end{array}$ & $\begin{array}{l}\mathbf{0 - 2 +} \\
\mathrm{N}(\%)\end{array}$ & $\begin{array}{l}\text { 3-11+ } \\
\mathrm{N}(\%)\end{array}$ & $\begin{array}{l}\text { 12-17+ } \\
\mathrm{N}(\%)\end{array}$ & $\begin{array}{l}\text { 18-39+ } \\
\mathrm{N}(\%)\end{array}$ & $\begin{array}{l}\mathbf{4 0 >} \\
\mathrm{N}(\%)\end{array}$ \\
\hline Blepharitis & $15(10.80)$ & $20(12.60)$ & $4(6.0)$ & $5(7.80)$ & $15(25.0)$ & $6(10.70)$ & $5(10.0)$ \\
\hline Conjunctivitis & $94(67.60)$ & 114(71.70) & $60(80)$ & $53(82.80)$ & $35(58.30)$ & $30(53.60)$ & $30(60.0)$ \\
\hline Keratitis & $30(21.60)$ & $25(15.70)$ & $4(6.0)$ & $6(9.30)$ & $10(16.70)$ & $20(35.70)$ & $5(30.0)$ \\
\hline Total & $139(46.60)$ & $159(53.40)$ & 68 & 64 & 60 & 56 & 50 \\
\hline
\end{tabular}

$\mathbf{N}=$ number of isolates

$\%=$ percentage frequency 
TABLE 4: PERCENTAGE SUSCEPTIBILITY OF ISOLATES

\begin{tabular}{|l|l|l|l|l|l|l|l|l|l|l|}
\hline Organisms & No of isolates & OFX & CPX & AUG & GENT & CEP & NA & SXT & PN & CHL \\
\hline S. aureus & 80 & 20 & 80 & 70 & 70 & 80 & 10 & 30 & - & 80 \\
S. albus & 65 & 30 & 20 & 80 & 60 & 80 & 10 & 25 & - & 80 \\
S. pyogenes & 20 & 20 & 40 & 90 & 20 & 70 & 30 & 35 & 90 & 75 \\
S. pneumoniae & 29 & 80 & 10 & 90 & - & 80 & - & 25 & 90 & 90 \\
S. viridans & 22 & 20 & 40 & 80 & 30 & 80 & 80 & 60 & 80 & 95 \\
S. faecalis & 5 & 20 & 40 & 80 & 100 & 20 & 100 & 55 & 80 & 70 \\
N. meningitidis & 1 & 100 & 100 & 100 & - & - & - & - & 100 & - \\
N. gonorrhoeae & 13 & 90 & 80 & 50 & 50 & 60 & 65 & - & 95 & 50 \\
M. catarrhalis & 10 & 10 & 20 & 20 & 50 & 60 & 70 & - & 10 & 20 \\
E. Coli & 15 & 20 & 40 & 20 & 70 & 50 & 50 & 90 & - & 80 \\
K. pneumoniae & 20 & 70 & 80 & 20 & 75 & 45 & 45 & 90 & - & 80 \\
P. mirabilis & 5 & 70 & 80 & 20 & 70 & 45 & 45 & 90 & - & 75 \\
H. influenzae & 26 & 80 & 80 & 100 & 40 & 20 & 20 & 60 & 5 & 95 \\
P. aeruginosa & 34 & 80 & 90 & 50 & 90 & 20 & 40 & 30 & - & 10 \\
\hline
\end{tabular}

OFX = Ofloxacin, $\mathrm{CPX}=$ Ciprofloxacin, $\mathrm{AUG}=$ Augumentin

GENT $=$ Gentamycin, $\mathrm{CEP}=$ Cephalexin, NA=Naldixic acid,

$\mathrm{SXT}=$ Sulfonamides and trimethoprim $\mathrm{CHL}=$ Chloramphenicol.

- Not susceptible 